\title{
O USO
}

\section{DE FERRAMENTAS}

DIGITAIS

NO ENSINO

\section{DE LÍNGUA INGLESA}

\section{PARA ALUNOS SURDOS:}

\section{O QUE DIZEM}

OS PROFESSORES?

\section{EL USO DE HERRAMIENTAS DIGITALES EN LA ENSEÑANZA DEL IDIOMA INGLÉS PARA ALUMNOS SORDOS: ¿QUÉ DICEN LOS PROFESORES?}

THE USE OF DIGITAL TOOLS IN ENGLISH LANGUAGE TEACHING FOR DEAF STUDENTS:

WHAT DO TEACHERS SAY ABOUT IT?

Matheus Lucas de Almeida*

Universidade Católica de Pernambuco

Antonio Henrique Coutelo de Moraes**

Universidade Católica de Pernambuco

Juliene Lopes Ribeiro Pedrosa***

Universidade Federal da Paraíba

\footnotetext{
* Doutorando em Ciências da Linguagem pela Universidade Católica de Pernambuco (UNiCAP). Atua nas áreas de bilinguismo, língua inglesa, tecnologias, educação de surdos e aquisição da linguagem. E-mail: matheus.lucas.a@gmail.com

** Doutor em Ciências da Linguagem pela Universidade Católica de Pernambuco (UNiCAP). Professor e Coordenador do curso de Letras e Professor do Programa de Pós-graduação em Ciências da Linguagem da UNiCAP. Atua nas áreas de aquisição, ensino, inglêsesurdez.E-mail: antonio.moraes@unicap.br 
RESUMO: No ano de 2020, as demandas e necessidades da educação de surdos se intensificaram com a crise sanitária da COVID19 que, infelizmente, perdura até os dias atuais. Assim, o objetivo deste artigo é analisar as concepções de professores que tiveram experiência com o ensino da língua inglesa para surdos durante a pandemia da COVID-19 acerca de suas experiências sobre o uso das Tecnologias Digitais da Informação e Comunicação (TDIC) com esses alunos. Para tal, buscamos nos fundamentar em Borges e Lima (2018), Kupske (2018), Moraes e Barros (2020), Almeida (2021), entre outros. O estudo possui uma abordagem qualitativa (TRIVIÑOS, 2010) e utiliza a análise de conteúdo (BARDIN, 2011). Os dados demonstram que as TDIC podem facilitar o acesso linguístico dos alunos surdos nas aulas de língua inglesa. Todavia, algumas especificidades devem ser respeitadas e processos formativos devem ser disponibilizados aos profissionais que trabalham com esses sujeitos.

PALAVRAS-CHAVE: Língua Inglesa. Ensino. Surdos. TDIC. Pandemia.

RESUMEN: RESUMEN: En el año 2020, las demandas y necesidades de la educación para sordos se intensificaron con la crisis de salud del COVID-19, que, lamentablemente, continúa hasta el día de hoy. Así, el objetivo de este artículo es analizar las concepciones de los docentes que tuvieron experiencia en la enseñanza de idioma inglés a sordos durante la pandemia COVID-19 sobre sus experiencias con el uso de las Tecnologías Digitales de la Información y la Comunicación (TDIC) con estos estudiantes. Para ello, buscamos basarnos en Borges y Lima (2018), Kupske (2018), Moraes y Barros (2020), Almeida (2021), entre otros. El estudio tiene un enfoque cualitativo (TRIVIÑOS, 2010) y utiliza el análisis de contenido (BARDIN, 2011) como herramienta. Los datos demuestran que TDIC pueden facilitar el acceso lingüístico de los estudiantes sordos en las clases de inglés. Sin embargo, hay que respetar algunas especificidades y procesos de formación deben ser puestos a disposición de los profesionales que trabajan con esos sujetos.

PALABRAS CLAVE: Idioma inglés. Enseñanza. Sordos. TDIC. Pandemia.

ABSTRACT: In 2020, the demands and needs of deaf education intensified with the health crisis of COVID-19, which, unfortunately, continues to this day. Thus, the objective of this article is to analyze the conceptions of teachers who had experience teaching the English language to the deaf during the COVID-19 pandemic about their experiences with the use of Digital Information and Communication Technologies (DICT) with these students. To this end, we sought to base our discussions on Borges and Lima (2018), Kupske (2018), Moraes and Barros (2020), Almeida (2021), among others. The study has a qualitative approach (TRIVIÑOS, 2010) and we use content analysis (BARDIN, 2011) on the data. The data demonstrate that DICT can facilitate the linguistic access of deaf students in English classes. However, some specificities must be respected, and training must be offered to professionals who work with these individuals.

KEYWORDS: English Language. Teaching. Deaf. DICT. Pandemic.

\section{INTRODUÇÃO}

A educação no Brasil possui diversas inconsistências e problemáticas; e a educação dos grupos minoritários é ainda mais afetada, como ocorre com os alunos surdos. Afinal, esses sujeitos só tiveram direito de acesso ao conhecimento reconhecido por lei, de modo a respeitar suas especificidades, há menos de duas décadas.

As demandas e necessidades do contexto educacional desse grupo crescem cada vez mais, tendo esses processos se intensificado, no ano de 2020, com a crise sanitária iniciada por conta da COVID-19 que, infelizmente, perdura até os dias atuais. Afinal, foi necessária a remodelação de todo o sistema de ensino e a sala de aula passou do espaço físico para o virtual, o que demanda que reflexões sejam realizadas acerca de como esse processo pode ocorrer de modo qualitativo e com equidade para todos.

Nesse ínterim, entendemos que apesar das ressignificações que estão ocorrendo no âmbito escolar, o professor é um sujeito que está e continuará ligado por muito tempo aos contextos de socialização do saber, quer sejam eles espaços físicos ou digitais. Acreditamos ser necessário utilizar as experiências e narrativas desses profissionais como base para a tomada de decisões pedagógicas e é importante que as práticas de (in)sucesso sejam compartilhadas para que, a partir delas, possamos compreender melhor o que precisa ser ressignificado (JOHNSON, 2004). 
O presente estudo busca analisar as concepções de professores que tiveram experiência com o ensino da língua inglesa para surdos durante a pandemia da COVID-19 acerca de suas experiências e concepções sobre o uso das Tecnologias Digitais da Informação e Comunicação (TDIC) com esses alunos. Para tal, o estudo conta com uma abordagem qualitativa (TRIVIÑOS, 2010) e utiliza a análise de conteúdo (BARDIN, 2011) como instrumento de análise.

Para responder o seguinte questionamento: como os alunos surdos tiveram acesso linguístico nas aulas de língua inglesa durante a pandemia da COVID-19 no ano de 2020? O estudo, além da introdução e considerações finais, divide-se em três partes. Inicialmente, são abordadas questões referentes às especificidades linguísticas do surdo e como esse sujeito, normalmente, acessa o conhecimento. Em seguida, discorre-se sobre os impactos que a COVID-19 causou no sistema educacional e, consequentemente, na educação de surdos. Por fim, são trazidas considerações de professores de língua inglesa que tiveram experiência de ensino com alunos surdos durante a pandemia da COVID-19 no ano de 2020.

\section{ACESSO LINGUÍSTICO DO SURDO NAS AULAS DE LÍNGUA INGLESA}

A Lei nº 10.436/2002 e o Decreto n 5.626/2005 foram avanços significativos na educação de surdos, tendo em vista que asseguram o direito à utilização da língua brasileira de sinais (LIBRAS) nos espaços educacionais. Todavia, os índices educacionais desses sujeitos apresentam discrepância em relação às séries de ensino nas quais estão inseridos (GAROLLA; CHIARI, 2003; CARRANCHO, 2012; ALMEIDA; SANTOS, 2016, 2017; SANTOS; CAVALCANTI; ALMEIDA, 2017; ALMEIDA, 2021).

Nesse contexto, ainda são incipientes as pesquisas que se debruçam sobre a aquisição de uma terceira língua (L3) por surdos. Muitas vezes, utiliza-se como justificativa para a não urgência desses estudos outras lacunas ainda não solucionadas, como a falta de proficiência em língua portuguesa (ALMEIDA, 2021). Sousa (2018), por exemplo, pontua que essa é uma área com poucas pesquisas tanto em nível nacional quanto internacional, o que sinaliza a urgência de maiores discussões sobre a temática.

Todavia, apesar das poucas discussões sobre o tema, alguns autores já têm demonstrado a possibilidade desse processo de aquisição (MELLO, 2002; SILVA, 2005; KILPATRICK, 2008; HERZIG, 2009; VANEK, 2009; MORAES 2012, 2018; SILVA, 2013; TAVARES; OLIVEIRA, 2014; PEREIRA; KLEIN, 2015; SOUSA, 2015; GONÇALVES, 2019; ALMEIDA, 2021).

Com base nas realidades analisadas, parece-nos ser um desafio para os profissionais envolvidos nesse processo as especificidades desse contexto. Afinal, como pontua Silva (2005, p. 70),

\footnotetext{
[h]oje a sala de aula de inglês na escola inclusiva pode ser comparada a um delta linguístico composto pelo inglês como língua-alvo, língua essa que o professor deve dominar, o português como língua majoritária na sala de aula e compartilhada pelo professor, alunos ouvintes e o intérprete, e a LIBRAS como língua minoritária e conhecida pelos alunos surdos e o intérprete. Três grandes "rios" são responsáveis pela formação deste delta: a inclusão do surdo no ensino regular, a obrigatoriedade do ensino de uma língua estrangeira no ensino público e o fato do professor não saber LIBRAS.
}

Portanto, tal processo envolve, no mínimo, três línguas: a língua de sinais que, normalmente, é a primeira língua (L1) dos surdos quando esses são filhos de pais surdos ou são apresentados a LIBRAS no início da infância, a língua portuguesa como segunda língua (L2), sendo essa preferencialmente na modalidade escrita e, por fim, a língua inglesa como terceira língua (L3), língua obrigatória nos ensinos fundamental e médio pela Base Nacional Curricular Comum (BNCC, 2017)

Além do bilinguismo há, também, a bimodalidade, visto que a LIBRAS é uma língua visual-espacial e o português e o inglês línguas orais-auditivas (SOUSA, 2018). Dessa forma, como sugerem Schenka-Ribeiro e Sholl-Franco (2018), é necessário a aplicação de metodologias que sejam coerentes com essas especificidades para que tenhamos um ensino com equidade para todos. 
Assim, a LIBRAS deve possuir um protagonismo significativo. Afinal, as interações das crianças com textos escritos ocorrem com o suporte da língua de sinais (BROCHADO, 2003). De acordo com Kupske (2018), esse suporte não se manifesta apenas com o par LIBRAS e língua portuguesa, mas, pode ocorrer, também, com o par LIBRAS e língua inglesa. Ademais, a comunidade surda tem garantido o direito ao uso da LIBRAS nas instituições de ensino, seja com o suporte do intérprete ou do professor (BORGES; LIMA, 2018).

Corroboramos Moraes e Barros (2020a) ao afirmarem que as barreiras comunicacionais existentes podem ser quebradas com a utilização do bilinguismo social, visto que esse permite o uso da língua de sinais como uma possibilidade para o alcance de uma outra língua. Afinal, a LIBRAS é um elemento identitário da comunidade surda e é por e com ela que esses sujeitos, normalmente, vivenciam suas experiências comunicativas de modo mais significativo (PESSANHA; SILVA, 2015).

Exatamente por isso, é importante que os profissionais que estão inseridos nos espaços de socialização do saber conheçam os sistemas linguísticos presentes - nesse caso, a língua de sinais, a língua portuguesa e a língua inglesa - no processo de aquisição (KUPSKE, 2018), além dos aspectos culturais que permeiam esses contextos (MORAES; BARROS, 2020a). Afinal, como propõe Johnson (2004), as questões culturais são extremamente importantes para a aquisição de uma língua adicional.

Através dos intercâmbios realizados com o suporte dessas línguas, os sujeitos podem se inserir de modo mais significativo em sociedade, visto que irão dispor de um leque linguístico mais amplo, que pode possibilitar a interação com diferentes grupos de pessoas, nos mais variados âmbitos sociais.

Todavia, é importante que algumas questões sejam consideradas, como a modalidade visual-espacial da língua desses sujeitos (e sua facilidade com materiais visuais) e a escrita - modalidade importante, visto que ela proporciona o acesso a diversos materiais dispostos em sociedade (SANTOS; CAVALCANTI; ALMEIDA, 2017).

Nesse cenário, a visualidade emerge, também, como um elemento potencializador que considera a especificidade linguística do sujeito surdo. Assim, como pontuam Borges e Lima (2018, p. 83), "[u]ma educação bilíngue para os estudantes surdos, com a valorização de estratégias de ensino que utilizem, predominantemente, recursos visuais, é essencial para que os surdos se apropriem, de forma adequada, de termos e conceitos necessários para o sucesso do processo de ensino e aprendizagem do inglês como LE’.

Ou seja, devido à modalidade de sua língua, esses sujeitos poderão ser beneficiados por práticas educacionais que explorem recursos visuais, como o uso de imagens e mapas mentais, por exemplo.

Outrossim, a modalidade escrita é a ideal a ser desenvolvida no ensino de línguas adicionais para surdos. Afinal, na realidade bilíngue, essa é a modalidade que eles utilizarão ao realizar práticas do dia a dia na língua adicional, como ler a bula de um remédio, ler uma notícia e escrever postagens nas redes sociais, por exemplo. Sendo assim, atividades com fins específicos de leitura e escrita são possibilidades que se mostram acessíveis ao aluno surdo.

De acordo com Kupske (2018), não é atípico que o inglês trabalhado na escola desconsidere as especificidades do aluno surdo. Portanto, é importante que o professor utilize adaptações que considerem as particularidades desses alunos. Dessa maneira, o docente "será capaz de não apenas 'incluir' o estudante surdo, mas dar acesso a um novo mundo e a novas culturas por meio da leitura em língua inglesa” (KUPSKE, 2018, p. 118). Nessa perspectiva, a escola surge como espaço que ajuda na redução de desigualdades e favorece oportunidades que intensificam a responsabilidade e respeito às diferenças (SCHENKA-RIBEIRO; SHOLL-FRANCO, 2018).

Ademais, acreditamos que língua não deve ser vista apenas como código, mas como discurso incorporado em diferentes contextos socioculturais (JOHNSON, 2004). Sendo assim, o professor precisa promover experiências educacionais que reflitam aquilo que os alunos vivenciam ou irão vivenciar em sociedade e, sempre que possível, deve conciliar as atividades de escrita e leitura com a realidade do alunado para que, assim, elas possuam funcionalidade social para os estudantes (ALMEIDA, 2021). 
Desse modo, é perceptível que os profissionais da educação necessitam realizar escolhas e adaptações didáticas que respeitem as especificidades do surdo para que ele tenha a oportunidade de aprender a língua inglesa podendo, assim, expandir suas possibilidades linguísticas e culturais (MORAES; BARROS, 2020b). Contudo, essa realidade que já se mostrava complexa sofreu impactos significativos devido à pandemia da COVID-19, como será discutido na próxima seção.

\section{IMPACTOS DA PANDEMIA NO ACESSO LINGUÍSTICO DO SURDO}

Os debates acerca da Covid-19 têm-se intensificado na Academia diante das incertezas provocadas pela pandemia (FAUSTINO; SILVA, 2020), cujos avanço e consequências requereram medidas rápidas e conscientes por parte de diversas esferas da atividade humana a fim de preservar a população (PIRES BRITO et al., 2020). Tais medidas, embasadas em uma sólida base científica, promovem e garantem o fortalecimento de ações estratégicas de enfrentamento.

Entretanto, ainda diante de tantas incertezas e lacunas provocadas pela pandemia, muitos professores e estudantes brasileiros permanecem em casa. Como bem apontam Faustino e Silva (2020, p. 57), "[...] o século XXI nos trouxe a era das ciências tecnológicas e da evolução da forma de como se aprende e como se ensina”. Certamente, temos vivenciado uma transformação educacional, que impacta em grande medida os usos que são feitos da linguagem.

Nesse sentido, estudantes têm buscado conhecer melhores possibilidades para a sua aprendizagem, bem como compreender o formato remoto de ensino. Entretanto, “[...] não há como negar a repercussão negativa e preocupante no setor educacional, tendo em vista as discussões sobre os rumos para a educação no país” (FAUSTINO; SILVA, 2020).

Em acompanhamento da interrupção e da resposta educacional à Covid-19, a UNESCO (2020) divulgou dados que mostram um impacto em cerca de $70 \%$ dos estudantes do mundo que, em face do atual contexto, se encontram em isolamento. De acordo com a UNESCO (2020), no pico, mais de 1,7 bilhão de estudantes foram afetados. Além disso, os dados demonstraram que o número de crianças, jovens e adultos que não frequentavam escolas ou universidades por conta da COVID-19 aumentava significativamente.

No caso de estudantes surdos, essa situação é ainda mais preocupante em função das especificidades linguísticas deste grupo. Afinal, como bem pontuam Shimazaki et al. (2020), a oficialização da LIBRAS como meio de comunicação da comunidade surda no Brasil, em 2002, com a Lei no 10.436, legitima o uso dessa língua nos espaços educacionais. As pesquisadoras complementam: “[...] com a oficialização, demandaram-se novas normatizações intrínsecas à primeira, como a regulamentação, a formação e o ensino da Libras, pelo Decreto n' 5626/2005” (SHIMAZAKI et al., 2020, p. 4).

Essas implementações, que ainda não apresentavam os resultados esperados quanto à inclusão dos surdos na sala de aula no que diz respeito ao reconhecimento e respeito das diferenças linguísticas, apresentam-se ainda mais distantes de atingir esses resultados em um período tão difícil como o da pandemia da COVID-19. Certamente, como colocam Shimazaki et al. (2020), há aí um desafio: exigir de educadores e intérpretes de LIBRAS/português mudanças em suas práticas - o que nem sempre ocorre adequadamente. "As desvantagens dos surdos em relação aos ouvintes, no âmbito educacional, consequentemente, no acesso aos conhecimentos científicos, mesmo com a presença do Tradutor e Intérprete de Língua Brasileira de Sinais - TILS - em sala, têm se constituído em uma disparidade visível" (SHIMAZAKI et al., 2020, p. 4).

Em termos de acesso linguístico, temos aí uma barreira considerável a ser transposta. Isso porque estudantes surdos em salas inclusivas, na maioria dos casos, necessitam da intermediação do conhecimento e da linguagem através do TILS, ou seja, esses profissionais são um escasso meio de acesso linguístico, e as dificuldades interpostas pela qualidade de acesso às redes impacta diretamente esse processo. Como se sabe, delays e quedas de conexão podem distanciar em grande medida o que o professor diz e o que o TILS consegue interpretar, por exemplo. 
Todo o exposto desvela, portanto, a necessidade de ir além da garantia de acesso e permanência de surdos na Educação Básica em conjunto aos demais alunos. É preciso, ainda, (re)pensar a manutenção das condições de permanência de modo a favorecer o desenvolvimento linguístico desses estudantes, sem incorrer, mais uma vez, em práticas e concepções oralistas de ensino (remoto).

Valendo-nos de uma releitura de Shimazaki et al. (2020), afirmamos que, em um espaço educacional ainda pouco convencional, sem conhecimento e domínio da língua de sinais, com práticas pedagógicas descontextualizadas e inexperiência nas plataformas digitais, as dificuldades se perpetuam e ganham força. O que repercute de maneira negativa no acesso, formação e identidade linguísticos do surdo, refletindo na aquisição das diversas línguas que circulam na educação.

Como bem colocam Faustino e Silva (2020), promover o ensino remoto a todo custo pode levar à exclusão de alunos, em vez de instalar uma educação sem fronteiras, especialmente no caso de estudantes que possuem alguma especificidade, como a surdez. Com intuito de aproximar realidades e transpor barreiras, instituições e educadores devem unir-se para compartilhar estratégias e experiências, além de propor intercâmbios entre estudantes, para que estes possam avançar com seus estudos.

Portanto, espera-se, como bem colocam Martins e Almeida (2020), que as TDIC sejam utilizadas como interfaces para a construção conjunta de aprendizagens, visando à potencialização da educação a partir de debates, pensamento crítico, criatividade, colaboração, e reflexões acerca das experiências proporcionadas pela pandemia. Mais além, pelo uso de uma comunicação efetiva e amorosa e de um currículo integrado com a realidade dos estudantes para o estabelecimento de uma educação de qualidade.

Acreditamos ser importante que os (in)sucessos vivenciados nesse complexo período sejam discutidos para que, assim, possamos nos direcionar a um contexto educacional que busque atender às demandas de todos os alunos. Dessa forma, na próxima seção, são realizadas análises sobre as experiências vivenciadas por professores de língua inglesa junto a alunos surdos durante a pandemia da COVID-19.

\section{ACESSO À LÍNGUA INGLESA POR ALUNOS SURDOS DURANTE A PANDEMIA DA COVID-19: COM A PALAVRA, OS PROFESSORES}

Seguindo as orientações de Bardin (2011), são analisados nessa seção os dados coletados junto a professores de língua inglesa acerca de suas percepções sobre o ensino de língua inglesa durante o período pandêmico para alunos surdos. Os dados foram coletados com a partir de um questionário disponibilizado online, no Google Forms, no dia 04 de dezembro de 2020 e encerrado no dia 07 de janeiro de 2021.

A pesquisa foi submetida ao comitê de ética da Universidade Federal da Paraíba e, no dia 01 de dezembro de 2020, foi aprovada com Certificado de Apresentação de Apreciação Ética de número 39512720.6.0000.5188. Os respondentes foram professores de língua inglesa e intérpretes de LIBRAS (que também atuam como professores de língua inglesa) que tiveram experiência com o ensino de inglês para surdos durante o ano de 2020. Todos os participantes assinaram o Termo de Consentimento Livre e Esclarecido (TCLE) concordando com a participação no estudo.

Os sujeitos da pesquisa atuam nas redes municipal, estadual, federal e privada. Além disso, trabalham nos seguintes estados do país: Santa Catarina (SC), São Paulo (SP), Tocantins (TO), Paraná (PR), Paraíba (PB), Pernambuco (PE) e Piauí (PI). Os respondentes lecionam nos ensinos fundamentais I e II, ensino médio, ensino técnico e educação de jovens e adultos (EJA). Em relação ao tempo em que trabalham com o ensino e/ou interpretação de inglês para surdos, as experiências variaram entre menos de um ano até mais de 15 anos.

Como critério de sistematização dos dados, identificamos os participantes pelas siglas P (quando professor) e PI (quando professor e intérprete de LIBRAS). Seguido da sigla, esses receberam um número referente à ordem que responderam às perguntas, a exemplo de: P1, para o primeiro professor que respondeu e PI1 para o primeiro professor e intérprete que respondeu e assim sucessivamente. Aqui, são analisadas as respostas pertinentes ao objetivo do estudo. 
Nas questões abertas do questionário, os participantes puderam expressar suas experiências, concepções e anseios em relação ao ensino de língua inglesa para surdos mediado pelas TDIC durante a pandemia, no ano de 2020, da COVID-19.

Inicialmente, ao serem questionados sobre suas experiências lecionando inglês para estudantes surdos, os discursos dos professores chamam atenção para as dificuldades inerentes à prática. P3, por exemplo, afirma que é "um desafio, mas com bastante respostas positivas de aprendizado, uso constantes de diversas ferramentas e adaptações no material didático.”

A afirmação de P3 ratifica a necessidade de adaptações nos materiais de alunos com especificidades. Afinal, para que esses possam ter um resultado positivo, é necessário que tenham acesso a materiais que respeitem e considerem suas particularidades físicas, cognitivas e linguísticas

Tal colocação pode ser confirmada com o relato de PI 3, ao afirmar que sua "experiência mostrou que ensinando com estimulação por meio da visualidade os surdos aprendem melhor e se sentem motivados”. Sendo assim, os materiais utilizados com esses indivíduos devem dar atenção aos aspectos visuais, pois eles possibilitam uma maior facilidade de acesso aos conteúdos nas aulas de língua inglesa (BORGES; LIMA, 2018; KUPSKE, 2018).

Como é possível perceber nos relatos dos profissionais, essas ressignificações podem, muitas vezes, ser mediadas pelas TDIC. Afinal, quando questionados sobre a utilização de ferramentas digitais nas aulas de língua inglesa, o uso de jogos foi bastante mencionado pelos respondentes, o que confirma que esses instrumentos são uma possibilidade para o ensino de línguas (TOMAZ, 2018), ou seja, surgem como ferramentas que podem ser mediadoras do conhecimento (SILVA; PACHECO, 2020)

Em relação aos jogos, P3 citou alguns que utilizou com seus alunos, a saber: Gartic, Memory Game Online e Hang Man Online. O Gartic é um jogo de adivinhação colaborativo no qual os membros de uma sala se revezam para desenhar palavras que são sugeridas pela plataforma. Ao passo que isso ocorre, os demais jogadores precisam adivinhar qual palavra está sendo representada pelo desenho para que possam pontuar.

Esse jogo surge como uma interessante possibilidade para o ensino de inglês para surdos mediado por tecnologias, visto que o caráter intuitivo do site beneficia a participação do alunado. Além disso, junto aos seus pares, esses podem construir seu arcabouço linguístico da língua alvo que está sendo estudada. A exploração de diferentes linguagens como o uso de imagens e desenhos, além de inserir a visualidade ao ensino e aprendizagem, também proporciona a exploração da criatividade do alunado, elementos importantes em aulas de línguas e que são recomendados pela BNCC (BRASIL, 2017).

O segundo jogo mencionado por P3, o Memory Game Online, é uma versão online do jogo da memória. Nele, os alunos precisam combinar as imagens que fazem referência a determinados termos ou sentenças. Dessa forma, ao utilizar esse tipo de atividade com seu aluno surdo, o professor pode trazer um conteúdo prático utilizado no dia a dia e fazer uso de tecnologias para "[...] produzir sentidos em práticas de letramento na língua inglesa" (BRASIL, 2017, p. 246), o que demonstra as contribuições positivas da ferramenta.

Além disso, P3 também mencionou o Kahoot!, uma plataforma baseada em jogos que utiliza testes de múltipla escolha que permitem a geração de pins que podem ser acessados por meio de um navegador da Web ou do aplicativo Kahoot!. Esta plataforma pode ser utilizada de modo individual ou coletivo, servindo para realizar revisões, introduzir tópicos e praticar determinadas habilidades. Nela, além da possibilidade de criação de Kahoots, há a disponibilização de diferentes kahoots de diversas temáticas e, em diferentes línguas, prontos.

A visualidade do Kahoot! parece contribuir com processo de ensino para alunos surdos. Além disso, é possível trazer temas transversais para as aulas, utilizando a língua inglesa como mediadora dessas discussões. Assim, o alunado consegue ampliar suas perspectivas de mundo tendo contato com diferentes patrimônios e manifestações culturais (BRASIL, 2017). 
O Kahoot! é uma plataforma que surgiu nas respostas de mais de um participante. Sendo seu uso, inclusive, justificado por P3 por ser um instrumento que "favorece a utilização do visual + língua". Além disso, o caráter interativo da ferramenta demonstra ser um dos fatores mais atraentes para os alunos, visto que esses, até mesmo a partir de seus celulares, podem participar das atividades propostas.

Ao serem questionados sobre a utilização de ferramentas tecnológicas junto a alunos surdos, P4 afirmou que quando

[...] trabalhava com alunos surdos (em um período pré-pandemia), utilizava aplicativos, dicionários ilustrados, apresentação de slides (o mais utilizado), filmes, curtas, entre outros. No entanto, é importante mencionar que era um momento em que a questão tecnológica não estava tão latente e a escola (que era uma escola pública municipal bilíngue) não tinha tantos recursos. Pode ser que agora ela tenha se adaptado ao período!

Fica perceptível, então, que a falta de instrumentos tecnológicos para se utilizar com os alunos ainda é algo presente nas instituições de ensino básico. Assim, evidencia-se a necessidade de investimento em materiais tecnológicos que possam ser usados no espaço escolar.

Em relação às ferramentas tecnológicas utilizadas com alunos surdos que trouxeram bons resultados, P4 relata que

[...] utilizava várias ferramentas, sempre no intuito de trazer a visualidade atrelada à língua, já que, se não mostrasse a língua inglesa em sua forma escrita aos alunos, não conseguiria caracterizar a minha aula como uma aula de língua estrangeira. À época, apresentação de slides e filmes (o uso do projetor em si) eram bem positivos à aprendizagem, e ajudavam alunos ouvintes também. O uso da lousa, por mais simples que pareça, também era essencial no contexto em que lecionava, com poucos recursos digitais.

No relato de P4, a visualidade e a modalidade escrita da língua surgem como estratégias que favorecem tanto os alunos surdos quanto os ouvintes. Essas colocações, além de corroborarem os pressupostos de Borges e Lima (2018) e Pereira e Krieger (2018) acerca da visualidade na educação de surdos, demonstram que em um espaço no qual há alunos surdos e ouvintes é possível que ambos os grupos se beneficiem com o suporte de uma práxis pedagógica que possibilita a aprendizagem (REIS; MORAIS, 2020).

Assim, percebe-se que mesmo utilizando elementos simples como a lousa, a aprendizagem é favorecida a esses grupos por conta do aspecto visual que é explorado. Dessa forma, seu uso se justifica porque sai-se do campo da abstração e parte-se para algo mais concreto e visual que, devido ao caráter visual-espacial da língua de sinais, favorece o processo de aprendizagem dos surdos.

Além disso, confirma-se a importância do trabalho com a modalidade escrita da língua alvo, tendo em vista que P4 afirma que caso não utilizasse essa modalidade não consideraria sua aula uma aula de língua adicional. Essa afirmação ratifica o que Moraes (2015, 2018) e Almeida (2021) propõem acerca do ensino de inglês para surdos: a modalidade escrita é a mais adequada a ser ensinada, pois ela respeita as especificidades desses sujeitos.

Aos serem questionados se utilizavam ferramentas tecnológicas antes da pandemia da COVID-19 com seus alunos surdos, P4 afirmou que

[...] o projetor era MUITO utilizado antes da pandemia; e ele oportuniza infinitas possibilidades de utilização. No entanto, avaliando de uma forma geral, até mesmo pensando nos alunos ouvintes com os quais trabalho hoje, penso que antes da pandemia nós explorávamos muito pouco os recursos digitais à nossa disposição. Para a pós-pandemia (se é que ela vai chegar rs), não me vejo trabalhando da forma que trabalhava antes, não me vejo trabalhando sem um computador e um projetor em sala, não me vejo utilizando tanto a lousa (e sim o espelhamento do word, por exemplo), não me vejo sem Kahoot! ou outros jogos online... Heranças (BASTANTE POSITIVAS) da pandemia!

Fica claro que, apesar das grandes disrupturas trazidas pela crise sanitária, alguns bons frutos puderam ser colhidos, já que houve um aumento significativo no uso das TDIC (SILVA; TEIXEIRA, 2020). É importante que reflexões sejam realizadas sobre como esses instrumentos tecnológicos que temos à nossa disposição podem favorecer o acesso linguístico do aluno surdo nas aulas de 
língua inglesa (ALMEIDA, 2021). Ademais, como é possível perceber no relato de P4, muitas de suas práticas foram ressignificadas permanentemente, visto que a/o respondente passou a perceber possibilidades pedagógicas que antes não eram cogitadas.

Grosso modo, muitos profissionais não utilizavam as TDIC anteriormente devido à falta de formação para tal (SILVA; TEIXEIRA, 2020). Nesse sentido, é importante que sejam ofertados processos formativos para a utilização das TDIC no ensino de línguas (ALMEIDA, 2021), tendo em vista que esse campo pode ser beneficiado pela utilização desses instrumentos (MATTAR, 2010; PRENSKY, 2010; FREI et al., 2011; FISCHER; KIPPER, 2016; SILVA; TEIXEIRA, 2020).

Portanto, percebe-se que o uso dessas ferramentas pode ser bastante produtivo, pois o outro surge como sujeito ativo no processo interacional (DANTAS; SANTOS, 2020) em uma relação de coparticipação entre os pares, no qual se dá voz aos conhecimentos, habilidades e capacidades do outro (RIBAS, 2018). Além disso, essas ferramentas colocam os aprendizes em uma posição mais ativa no processo de construção de seu conhecimento (JOHNSON, 2004; ALMEIDA, 2021).

\section{CONSIDERAÇÕES FINAIS}

O artigo em tela, de caráter qualitativo descritivo, seguiu as orientações de Triviños (2010) e Bardin (2011) para analisar as concepções de professores que tiveram experiência com o ensino da língua inglesa para surdos durante a pandemia da COVID-19, acerca de suas experiências e concepções sobre o uso das Tecnologias Digitais da Informação e Comunicação (TDIC) com esses alunos.

Nesse sentido, foi possível verificar que a educação brasileira possui diversas inconsistências e problemáticas, principalmente no tocante à educação de grupos minoritários, como no caso dos alunos surdos. As demandas e necessidades educacionais desse grupo crescem cada vez mais, tendo esses processos se intensificado com a crise sanitária iniciada por conta da COVID-19 no ano de 2020 que, infelizmente, ainda perdura.

Inicialmente, buscamos discutir o acesso linguístico do surdo em língua inglesa, momento em que constatamos que ainda são incipientes as pesquisas que se debruçam sobre a aquisição de uma L3 por surdos. Em um segundo momento, abordamos alguns impactos da COVID-19 no acesso linguístico do surdo, o que permitiu visualizar que há uma necessidade de ir além da garantia de acesso e permanência de surdos na Educação Básica em conjunto aos demais alunos. Afinal, é preciso (re)pensar modos de manutenção das condições de permanência de forma a favorecer o desenvolvimento linguístico desses estudantes, sem incorrer, mais uma vez, em práticas e concepções oralistas de ensino (remoto). Em um terceiro momento, debruçamo-nos sobre nossos dados a fim de analisar o acesso da língua inglesa por alunos surdos durante a pandemia da COVID-19 a partir de narrativas de professores, o que nos possibilitou interessantes reflexões sobre o uso das TDIC nesse contexto.

Com base no que foi discutido ao longo de nosso estudo, parece-nos evidente que, apesar das grandes dificuldades impostas pela pandemia, bons frutos podem ser colhidos a partir do uso das TDIC em aulas de língua inglesa frequentadas por surdos. Ademais, o aumento no uso das TDIC evidencia a importância de reflexões sobre formas de utilização desses instrumentos tecnológicos de modo a favorecer o acesso linguístico do aluno surdo nas aulas de língua inglesa. Além disso, devido ao seu caráter multimodal, visualizamos nas TDIC uma possibilidade para o ensino e aprendizagem de surdos.

Nesse sentido, é necessário que ações sejam realizadas frente à essa realidade que, apesar de estar começando a dar passos para uma educação mais inclusiva, ainda necessita de significativas mudanças. Isto é, apesar de os dados sinalizarem que as TDIC representam uma possibilidade de construção do conhecimento nas aulas de língua inglesa, é importante que sejam ofertadas formações para a utilização desses instrumentos, uma vez que ainda há insegurança por parte de professores quanto a essas ferramentas.

Por fim, os resultados aqui encontrados nos trazem esperança em relação ao atual contexto educacional de ensino de línguas adicionais para surdos. Afinal, é possível observar que, independentemente de suas especificidades comunicacionais, esses podem adquirir uma segunda ou terceira língua. Todavia, é necessário que suas especificidades sejam consideradas durante as escolhas 
didático-metodológicas utilizadas com esses. Assim, o presente estudo surge como uma possibilidade de reflexão sobre esse paradigma educacional que a comunidade surda tem vivenciado, visto que ele propõe novas possibilidades educacionais para que as narrativas de sucesso sejam maiores que as de insucesso no que concerne à aquisição de uma L3 por aprendizes surdos.

\section{REFERÊNCIAS}

ALMEIDA, M. L. TDIC no ensino de língua inglesa: possibilidades na educação de surdos. 2021. Dissertação (Mestrado Profissional em Linguística e Ensino) - Programa de Pós-Graduação em Linguística e Ensino, Universidade Federal da Paraíba, 2021.

ALMEIDA, M. L.; SANTOS, I. C. A argumentação no processo de leitura pela pessoa surda. In: JORNADA DE INICIAÇÃO CIENTÍFICA, 18., UNICAP, 2016, Recife. Anais... Recife: FASA, 2016. p. 234.

ALMEIDA, M. L.; SANTOS, I. C. A experiência de rodas de leitura em língua portuguesa com surdos do ensino fundamental. In: ENCONTRO REGIONAL DE LINGUÍSTICA (ERELIN), 3., 2017, Garanhuns. Anais... Garanhuns: UPE, 2017. p.100.

AMORIM, É. K. N.; GOMES, T. E. O ensino da língua inglesa e a BNCC: um estudo de caso. Revista Educação e Humanidades, v. 1, p. $417-435,2020$

BARDIN, L. Análise de conteúdo. Lisboa: Edições 70, 2011.

BORGES, E. A.; LIMA, L. R. O ensino e o aprendizado do inglês como língua estrangeira em uma escola bilíngue para surdos: reflexões sobre a prática pedagógica. Revista Sinalizar, v.3, n.2, p. 68-86. 2018. Disponível em: https://doi.org/10.5216/rs.v3i2.55515. Acesso em: 26 jan. 2022.

BRASIL. Decreto $n^{\circ} 5.626$, de 22 de dezembro de 2005. Regulamenta a Lei no 10.436, de 24 de abril de 2002, que dispõe sobre a Língua Brasileira de Sinais - Libras, e o art. 18 da Lei no 10.098, de 19 de dezembro de 2000. Brasília, 22 de dezembro de 2005, 184 da Independência e $117^{\circ}$ da República. Disponível em: http://www.planalto.gov.br/ccivil03/ ato2004-2006/2005/decreto/d5626.htm. Acesso em: 12 mar. 2017.

BRASIL. Lei $n^{\circ}$ 10436, de 24 de abril de 2002. Dispõe sobre a Língua Brasileira de Sinais - Libras e dá outras providências. Brasília, 24 de abril de 2002, $181^{\circ}$ da Independência e $114^{\circ}$ da República. Disponível em: http://www6.senado.gov.br/legislacao/ListaPublicacoes.action?id=234606. Acesso em: 12 mar. 2017.

BRASIL. Ministério da Educação. Base Nacional Comum Curricular. Versão final.

Brasília: Ministério da $2017 . \quad$ Educação, Disponível

http://basenacionalcomum.mec.gov.br/abase/ Acesso em: 02 dez 2020.

BROCHADO, S. M. D. A apropriação da escrita por crianças surdas usuárias da língua de sinais brasileira. 2003.431 f. Tese (Doutorado em Letras) - Faculdade de Ciências e Letras de Assis, Universidade Estadual Paulista Júlio de Mesquita Filho, Assis, 2003.

CARRANCHO, A. S. A representação social da surdez: entre o mundo acadêmico e o cotidiano escolar. In: LODI, A. C. B.; MÉLO, A. D. B.; FERNANDES, E. (org). Letramento, bilinguismo e educação de surdos. Porto Alegre: Mediação, 2012. p. 39-50.

DANTAS, W.; SANTOS, E. C. dos. As ideias linguísticas do círculo de Bakhtin na base nacional comum curricular (BNCC). Macabéa - Revista Eletrônica do Netlli, Crato, v. 9., n. 3., p. 287-303, 2020. Disponível em: http://periodicos.urca.br/ojs/index.php/MacREN/article/view/2401/1810. Acesso em: 01 abr. 2021. 
FAUSTINO, L. S. S.; SILVA, T. F. R. S. Educadores frente à pandemia: dilemas e intervenções alternativas para coordenadores e docentes. Boletim de Conjuntura (BOCA), Boa Vista, v.3, n.7, p. 53-64, 2020. Disponível em: https://revista.ufrr.br/boca. Acesso em: 27 ago. 2020 .

FISCHER, S. R; KIPPER, D. Estratégias e recursos visuais na aprendizagem da língua inglesa por alunos surdos. In: SEMINÁRIO NACIONAL DE PESQUISA EM EDUCAÇÃO, 6., 2016, Santa Cruz do Sul. Anais... Santa Cruz do Sul: EDUNISC, 2016. [14] p.

FREI, S. et al. Integrating technology into the curriculum. Huntington beach, CA: Shell Education, 2011.

GAROLLA, L. P; CHIARI, B. M. Protocolo para avaliação da compreensão de leitura em crianças deficientes auditivas. Pró-Fono. Revista de Atualização Científica, Barueri, SP, v. 15, n. 3, p. 325-334, set./dez. 2003.

GARTIC. Disponível em: https://gartic.com.br/. Acesso em: 10 fev. 2020.

GONÇALVES, M.de. M. Caminhos metodológicos no processo de ensino aprendizagem de inglês para o acadêmico visual sob as lentes bakhtinianas: possibilidades e construções. 2019. Tese (doutorado) - Universidade Federal de Mato Grosso, Instituto de Linguagens, Programa de Pós-Graduação em Estudos da Linguagem, Cuiabá, 2019. Disponível em: https://ri.ufmt.br/bitstream/1/1977/1/TESE_2019_M\%c3\%a1rcia\%20de\%20Moura\%20Gon\%c3\%a7alves.pdf. Acesso em: 12 fev. 2020.

HANG Man Online. Disponível em: https://matchthememory.com. Acesso em: 20 fev.20210

HERZIG, M. P. Understanding the motivation of deaf adolescent Latino struggling readers. Tese (Doutorado em Educação) San Diego: University of California, 2009.

JOHNSON, M. A philosophy of second language Acquisition. London, Yale University Press, 2004.

KAHOOT!. Disponível em: https://matchthememory.com/. Acesso em: 20 fev. 2020.

KILPATRICK, J. E. Jr. Students who are deaf/hard of hearing with interpreters in the foreign language classroom. 2008. Tese (Doutorado em Filosofia) - Kansas: University of Kansas, 2008.

KUPSKE, F. F.. Língua inglesa como terceira língua: considerações sobre o ensino de línguas estrangeiras para estudantes surdos na educação básica brasileira. Dialogia, v. $0, \quad$ p. 109-120, 2018. Disponível em: https://periodicos.uninove.br/dialogia/article/view/6722/3708. Acesso em: 20 fev. 2020.

MATTAR, J. Games em educação: como os nativos digitais aprendem. São Paulo: Pearson Prentice Hall, 2010.

MARTINS, V.; ALMEIDA, J. Educação em tempos de pandemia no Brasil: saberesfazeres escolares em exposição nas redes. Revista Docência e Cibercultura, [S.1.], v. 4, n. 2, p. 215-224, ago. 2020. Disponível em: https://www.e-publicacoes.uerj.br/index.php/redoc/article/view/51026. Acesso em: 30 ago. 2020.

MELLO, H. A. B. De. "O português é uma alavanca para que eles possam desenvolver o inglês": eventos de ensino-aprendizagem em uma sala de aula de ESL de uma escola "bilíngüe". Tese (Doutorado em Lingüística Aplicada) - Instituto de Estudos da Linguagem, Universidade Estadual de Campinas, Campinas, 2002. 
MEMORY Game Online. Disponível em: https://matchthememory.com/. Acesso em: 20 fev. 2020.

MORAES, A. H. C. A triangulação Libras-português-inglês: relatos de professores e intérpretes de Libras sobre aulas inclusivas de língua estrangeira. 2018. Tese (Doutorado em Ciências da Linguagem) - Programa de Pós-graduação em Ciências da Linguagem, Universidade Católica de Pernambuco, Recife, 2018.

MORAES, A. H. C. Descrição do desenvolvimento linguístico em língua inglesa por seis surdos: novos olhares sobre o processo de aquisição de uma língua. 2012. Dissertação (Mestrado em Ciências da Linguagem) - Programa de Pós-graduação em Ciências da Linguagem, Universidade Católica de Pernambuco, Recife, 2012.

MORAES, A. H. C.; BARROS, S. M. A Socio-Emancipatory Perspective on the Teaching of English as a Foreign Language to the Deaf. Research on Humanities and Social Sciences, v. 10, p. 1-7, 2020a.

MORAES, A. H. C; BARROS, S. M. MARIA. Reflections on policies which guide English language teaching to the deaf in Brazil. Brazilian Journal of Development, v. 6, p. 81577-81589, 2020 b.

PEREIRA, I; KRIEGER, C. F. Z. Tecnologias na educação de surdos. In: Alaim Souza Neto. (org.). Educação, aprendizagem e tecnologias: relações pedagógicas e interdisciplinares. São Paulo: Pimenta Cultural, 2018, v. 1, p. 167-193. Disponível em: http://10.31560/pimentacultural/2018.914. Acesso em: 15 fev. 2020.

PEREIRA, K. Á; KLEIN, M. Práticas de professores de alunos surdos e o ensino de língua estrangeira na educação de surdos. In: REUNIÃO NACIONAL DA ANPED, 37., 2015, Florianópolis. Anais... Florianópolis: UFSC, 2015. p. 1-18.

PESSANHA, A. P. B.; SILVA, S. P. O ensino de língua inglesa a alunos surdos. In: Cadernos do CNLF (CiFEFil), v. XIX, p. 140-159, 2015.

PIRES BRITO, S.; BRAGA, I.; CUNHA, C.; PALÁCIO, M.; TAKENAMI, I. Pandemia da COVID-19: o maior desafio do século XXI. Vigilância Sanitária em Debate: Sociedade, Ciência \& Tecnologia (Health Surveillance under Debate: Society, Science \& Technology) - Visa em Debate, v. 8, n. 2, p. 54-63, 28 abr. 2020.

PRENSKY, M. Teaching digital natives: partnering for real learning. Thousand Oaks, CA: Corwin, 2010.

REIS, M. B. de F., MORAIS, I. C. V. de. Inclusão dos surdos no Brasil: do oralismo ao bilinguismo. Revista UFG, Goiânia, v.20, n 26, 2020. Disponível em: https://www.revistas.ufg.br/revistaufg/article/view/62052. Acesso em: 10 fev. 2021.

RIBAS, F. C. Base Nacional Comum Curricular e o ensino de língua inglesa: refletindo sobre cidadania, diversidade e criticidade à luz do letramento crítico. Domínios de lingu@gem, v. 12, p. 1784-1824, 2018. Disponível em: https://seer.ufu.br/index.php/dominiosdelinguagem/article/view/40608. Acesso em: 15 abr. 2021.

SANTOS, I. C. dos; CAVALCANTI, W. M. A.; ALMEIDA, M. L. Havia uma leitura no meio do caminho da pessoa surda: considerações acerca da aquisição da língua portuguesa como segunda língua. Letra Magna (Online), v. 13, p. 1, 2017. Disponível em: http://www.letramagna.com/artigos_20/artigo10_20.pdf. Acesso em: 11 fev. 2021.

SCHENKA-RIBEIRO, N; SHOLL-FRANCO, A. Desafios educacionais em contextos multilíngues de ensino: uma proposta curricular inclusiva com línguas de sinais e neurociências. In: Colóquio Luso-Brasileiro De Educação - COLBEDUCA, 2018 , Braga. Anais... Joinville: UDESC - Universidade do Estado de Santa Catarina, 2018. v. 3. 
SHIMAZAKI, E. M.; MENEGASSI, R. J.; FELLINI, D. G. N. Ensino remoto para alunos surdos em tempos de pandemia. Praxis educativa, vol. 15, e2015476, p. 1-17, 2020. https://doi.org/10.5212/PraxEduc.v.15.15476.071

SILVA, C. C. S. C; TEIXEIRA, C. M. S. O uso das tecnologias na educação: os desafios frente à pandemia da covid-19/ the use of technologies in education: the challenges facing the covid-19 pandemic. Brazilian Journal of Development, v. 6, p. 70070-70079, 2020. Disponível em: https://brazilianjournals.com/index.php/BRJD/article/view/16897. Acesso em: 20 jan. 2021.

SILVA, C. M. O. O surdo na escola inclusiva aprendendo uma língua estrangeira (inglês): um desafio para professores e alunos. 2005. Dissertação (Mestrado) - Programa de Pós Graduação em Linguística Aplicada, Universidade de Brasília, Brasília, 2005.

SILVA, M. C. C. Aprendizagem da língua inglesa como terceira língua (L3) por aprendizes surdos brasileiros: investigando a transferência léxico-semântica entre línguas de modalidades diferentes. 2013. Tese (Doutorado em Letras) - Programa de PósGraduação em Letras, Pontifícia Universidade Católica do Rio Grande do Sul, Porto Alegre, 2013.

SILVA, S. R; PACHECO, C. A. Currículo do ensino de língua inglesa e uso de tecnologias digitais previstos na BNCC. Revista eletrônica de educação (são carlos), $\quad$ v. $\quad 14, \quad$ p. $\quad 1, \quad 2020 . \quad$ Disponível em: http://www.reveduc.ufscar.br/index.php/reveduc/article/view/3046. Acesso em: 20 fev. 2021.

SOUSA, A. N. de. O desenvolvimento da escrita de surdos em português (segunda língua) e inglês (terceira língua): semelhanças e diferenças. Revista Brasileira de Linguistica Aplicada, Belo Horizonte, v. 18, n. 4, p. 853-886, 2018. Disponível em: https://www.scielo.br/j/rbla/a/Qp9K5XYVrVczRdhz8pWQRVG/?lang=pt. Aceso em: 20 fev. 2021.

SOUSA, A. N. Educação plurilíngue para surdos: uma investigação do desenvolvimento da escrita em português (segunda língua) e inglês (terceira língua). 2015. Tese (Doutorado). Programa de Pós-Graduação em Linguística, Universidade Federal de Santa Catarina, Florianópolis: 2015.

TAVARES, K. C. A; OLIVEIRA, A. P. P. De. Libras no ensino de inglês mediado pelas novas tecnologias: desafios e possibilidades. Revista Brasileira de Linguistica Aplicada, v. 14, p. 1045-1072, 2014. http://dx.doi.org/10.1590/1984-639820145631.

TOMAZ, C. R. L. F. O uso das tecnologias digitais de informação e comunicação para aprendizagem bilíngue do surdo. In: CONGRESSO SOBRE TECNOLOGIAS NA EDUCAÇÃO, 5., 2020, João Pessoa. Anais... João Pessoa: UFPB, 2020. [p.10].

TRIVIÑOS, A. N. S. Introdução à pesquisa em ciências sociais: a pesquisa qualitativa em educação. 1. ed. - 19. reimpr. - São Paulo: Atlas, 2010 .

UNESCO - United Nations Educational, Scientific and Cultural Organization. COVID-19 Educational Disruption and Response. UNESCO [2020]. Disponível em: https://en.unesco.org/covid19/educationresponse. Acesso em 30/08/2020.

VANEK, M. Language learning and deafness. Tese (Doutorado em Língua Inglesa e Literatura). Brno: Masaryk University, 2009.

\section{()(1) $\circledast$}

Recebido em 02/05/2021. Aceito em 03/07/2021. 